\title{
Directed evolution of gold nanoparticle delivery to cells
}

\author{
$\mathrm{Na} \mathrm{Li}{ }^{\mathrm{a}}$, Timothy Larson ${ }^{\mathrm{b}}$, Hong H. Nguyen ${ }^{\mathrm{a}}$, Konstantin V. Sokolov ${ }^{\mathrm{b}}$, and Andrew D. \\ Ellington $^{\mathrm{a}}$ \\ Andrew D. Ellington: andy.ellington@mail.utexas.edu \\ aDepartment of Chemistry and Biochemistry, Institute for Cell and Molecular Biology, University of \\ Texas at Austin, Austin, TX, 78712, USA. Fax: 512471 7014; Tel: 5122323424 \\ bDepartment of Biomedical Engineering, University of Texas at Austin Austin, TX, 78712, USA
}

\begin{abstract}
A newly selected anti-receptor (anti-EGFR) aptamer was conjugated to gold nanoparticles via a facile hybridization method and was found to specifically and quantitatively direct the delivery of gold nanoparticles to cells expressing EGFR through receptor-mediated endocytosis.
\end{abstract}

Gold nanoparticles (GNPs) have been used for applications in medicine and research, including cancer detection, ${ }^{1}$ drug delivery, ${ }^{2}$ and siRNA or anti-sense DNA transfection. ${ }^{3,4}$ GNPs have frequently been coated with nucleic acids, either to facilitate the delivery of the nucleic acids to cells, or to facilitate the internalization of the GNPs into cells. Interestingly, some nucleic acids, such as anti-sense DNA molecules, seem to abet non-specific delivery of GNPs into many different cells. ${ }^{4}$ It is unclear why this is, although other researchers worked with charged nanoparticles have also observed that charge can strongly influence the degree of delivery. 5,6 One hypothesis is that there is a competition between non-specific and specific delivery that is mediated by the affinity of specific nucleic acid shapes (aptamers) relative to the general negative charge present on all nucleic acids. In order to assess this hypothesis, we have attempted to generate aptamers de novo for a specific receptor, and then show that these aptamers guide GNPs to be taken up specifically, rather than nonspecifically. To the extent that this hypothesis can be confirmed, it provides grounds for the targeting nanoparticle conjugates, and for further experiments to examine how the physical properties of nucleic acids parse specific and non-specific uptake and escort.

As a starting point for selection, we targeted a receptor that we knew would undergo endocytotic internalization, and that has been shown to be involved in many types of human cancers, EGFR ${ }^{7}$. In order to identify aptamers specific for EGFR, we generated a RNA pool that spanned 62 random sequence positions (N62) and carried out 12 rounds of selection against the purified extracellular domain of human EGFR. The selected binding species increased from $0.2 \%$ in Round 0 to $54 \%$ in Round 12, with no concomitant increase in background binding. Thirty clones from the Round 12 pool were sequenced and one aptamer predominated - J18 with a $\mathrm{K}_{\mathrm{d}}$ about $7 \mathrm{nM}$ (Figure S1).

In order to ensure that binding to the extracellular domain of EGFR in vitro translated into binding to the protein in the context of the cell surface we assayed Aptamer J18 by flow cytometry. A431 epidermoid carcinoma cells express an abnormally high level of EGFR (13 million receptors per cell) and are used as a model cell line for the characterization of

Correspondence to: Andrew D. Ellington, andy .ellington@mail .utexas .edu.

Electronic Supplementary Information (ESI) available: [The Supplementary Material deals with the details of aptamer selection, conjugation, and characterization. The microscopy methods employed are described in greater detail]. See DOI: 10.1039/b000000x/ 
EGFR. ${ }^{8,}{ }^{9}$ MDA-MB-435 breast cancer cells were found to be EGFR deficient and were used as a negative control. ${ }^{10}$ Aptamer J18 and unselected N62 pool RNA were labeled with phycoerythrin (PE) and incubated with trypsinized cells. ${ }^{11}$ Aptamer binding was compared to a PE-labeled anti-EGFR antibody and IgG. Both the PE-labeled Aptamer J18 and the PElabeled anti-EGFR antibody showed significant binding to A431 cells and but not MDAMB-435 cells (Figure S2). Little or no binding was seen with the negative controls (pool RNA or IgG). Aptamer J18's binding to A431 was inhibited by the therapeutic anti-EGFR antibody 225. The specificity of binding was further explored by confocal microscopy. Consistent with the flow cytometry data, there was strong signal for A431 cells labeled with PE-labeled Aptamer J18 (Figure S3C) but not A431 cells alone (Figure S3A) nor A431 cells labeled with PE-labeled unselected N62 pool RNA (Figure S3B). In addition, Aptamer J18's binding to A431 cells was blocked by both EGF (Figure S3D) and antibody 225 (Figure S3F), but not by the orthogonal cytokine FGF (Figure S3E) nor by an anti-transferrin antibody (Figure S3G).

We also assayed the specificity of the aptamer for different forms of EGFR. The aptamer binds specifically to EGFR, and not to the related human protein ErbB2, or to mouse EGFR (Figure S4A). The purified EGFR protein used for selection is dimeric (via an IgG fusion), but can be rendered into a monomer by the addition of $5 \mathrm{mM}$ DTT (Figure S4B). As shown in Figure S4A, Aptamer J18 has a similar affinity for both the EGFR dimer and monomer in vitro.

Overall, the specificity of the aptamer for EGFR in vitro and in the context of the cell surface implied that it should be taken up specifically, as well. To explore and quantify the extent to which Aptamer J18 could enter cells we developed a flow cytometry-based assay with PE-labeled Aptamer J18. Aptamer J18 on the cell surface is sensitive to nuclease treatment, while any internalized aptamer should be protected. Therefore, we used Riboshredder, a cocktail of RNases, to parse these two populations of aptamer. Binding assays were also carried out on ice to confirm that Aptamer J18 on the cell surface could be largely degraded by Riboshredder treatment (Figure 1A), as it is known that low temperatures inhibit receptor-mediated internalization. Fluorescent signal due to the aptamer was indeed almost entirely removed (>99\%) by Riboshredder treatment (Figure 1B, left). However, after incubating with cells at $37^{\circ} \mathrm{C}$ for $30 \mathrm{~min}$, about $35 \%$ of Aptamer J18 was protected, presumably due to internalization (Figure 1B, right). Similarly, the Tan group used trypsinization of cell surface proteins to demonstrate the internalization of an anti-CEM DNA aptamer. ${ }^{12}$ However, nucleases specific for the targeting reagent are more likely to give an accurate representation of internalization, since cells can be adversely affected by trypsinization and many aptamers are able to bind to targets on trypsinized cells. ${ }^{11}$

If the negatively charged aptamer targeting reagent can bind specifically to EGFR and be taken up into cells by endocytosis, we hypothesize that this should allow specific targeting of GNPs, rather than non-specific uptake of the nanoparticles. ${ }^{13}$ Aptamer J18 was conjugated to $20 \mathrm{~nm}$ diameter GNPs (Ted Pella) by coating the GNPs with DNA oliognucleotides (capture oliognucleotides) and hybridization of an extended aptamer complementary to the capture oligonucleotide. ${ }^{14}$ Instead of aging the oligonucleotides-GNP conjugate at $25^{\circ} \mathrm{C}$ for $24-48$ hours, ${ }^{14}$ the GNPs and 3 -biotinylated capture oligonucleotides were heated separately at $80^{\circ} \mathrm{C}$ and then mixed rapidly and incubated for an additional $5 \mathrm{~min}$ at $80^{\circ} \mathrm{C}$.

In order to assess the surface coverage of the GNP the capture oligonucleotide was removed by treatment with DTT and quantitated via $8 \%$ denaturing PAGE. There were about 300 capture oligonucleotides per GNP, which is similar to what was previously seen with the slower aging method. ${ }^{14}$ Some $0.3 \mu \mathrm{M}$ of aptamer was incubated with the oligonucleotide- 
GNP conjugates at $80^{\circ} \mathrm{C}$ for 3 min, leading to a loading of about 30 aptamers per GNP. SA$\mathrm{PE}$ was subsequently added to the biotinylated capture oligonucleotide in order to allow flow cytometry assay and confocal microscopy.

The Aptamer J18-GNP conjugates were incubated with A431 (Figures 2A and B) and with MDA-MB-435 cells (Figure 2C) at a concentration of $7 \times 10^{11}$ particles $/ \mathrm{mL}$. Only specific binding was observed, including with darkfield imaging (data not shown). The flow cytometry-based internalization assay also indicated that Aptamer J18-GNP conjugates only entered A431 cells. When Aptamer J18-GNP was incubated with A431 cells at $37^{\circ} \mathrm{C}$ about $70 \%$ of the fluorescent signal remained after Riboshredder treatment (Blue line, Figure 2B). However, there appeared to be some GNP protection of the aptamer from Riboshredder, as about 20\% fluorescent signal remained after Riboshredder treatment of Aptamer J18-GNP bound to cells while on ice (Blue line, Figure 2A). Nucleic acids bound to GNP has previously been shown to be partially resistant to nuclease digestion, possibly because of the extensively charged surface and resultant high local salt concentrations. ${ }^{15,16}$

Fluorescently-labeled cells were transferred to an 8-chamber slide and imaged via confocal microscopy (Figure 3). As with flow cytometry, little fluorescence was observed in negative controls (unselected N62 pool RNA-GNP on ice and at $37^{\circ} \mathrm{C}$; Figures 3B and E). When cells and Aptamer J18-GNP were incubated on ice, fluorescence was mainly apparent on the cell surface (Figure 3C). The signal was reduced but still visible after Riboshredder treatment (Figure 3D). In contrast, significant fluorescent signal was localized inside A431 cells when the Aptamer J18-GNP conjugates was incubated at $37^{\circ} \mathrm{C}$ (Figures $3 \mathrm{~F}$ and G). Similar experiments with the cell line MDA-MB-435 showed no signal above background (data not shown).

These results demonstrate that aptamers against cell surface receptors can lead to the specific internalization of GNP via these receptors. These results contrast with the demonstration that DNA molecules coupled to the surfaces of GNP mediate the non-specific uptake of these nanoparticles by many cell types. ${ }^{13}$ If so, then it might have been expected that our aptamer-conjugated nanoparticles should also have been taken up non-specifically, given that the number of charges and charge density on our particles was similar to those previously described. For example, there were roughly 12000 phosphodiester bonds $/ 20 \mathrm{~nm}$ particle in our experiments versus 2,240 phosphodiester bonds/13 $\mathrm{nm}$ particle in previous work. The roughly four-fold greater number of charges on our particles would have been spread over a roughly 2.5 -fold greater surface area, meaning that the overall surface charge density differed by a factor of 2.5. In the current work we used much lower concentrations of nanoparticles ( $1 \mathrm{nM}$ versus $60 \mathrm{nM}$ ) and exposed them to cells for shorter times (30 minutes rather than days). Our results speak to the specific internalization that would likely be observed in conjunction with nanoparticle circulation in vivo.

One explanation for the difference in specificity is that when a negatively charged GNP can avail itself of a specific uptake mechanism it does so in preference to non-specific mechanisms, including binding to positively charged proteins in solution. This would be an important finding for two reasons. First, the non-specific uptake of untargeted GNP puts them at a decided disadvantage for in vivo applications, since it might be anticipated that multiple different organs and tissues would accumulate the nanoparticles, potentially compromising imaging signals, potentiating side-effects from therapeutics, and leading to long-term toxicity. Second, a wide variety of aptamers have been isolated against biomedically relevant targets including growth factors and cell surface biomarkers, ${ }^{17}$ and thus a host of new applications for aptamer-GNP conjugates may now be indicated. In this regard, aptamer-GNP conjugates have already proven to be useful as in vitro diagnostics paving the way for their in vivo application. ${ }^{18,19}$ 
By demonstrating that directed evolution of receptor-specific nucleic acids can overcome non-specific absorption and internalization of GNP, these and similar result with other aptamers ${ }^{18}$ open the way to further therapeutic and other applications of nanoparticles. In particular, GNPs are ideal imaging reagents because they can provide colorimetric contrast induced by surface plasmon resonance, ${ }^{20,21}$ and they also provide absorption contrast for photothermal therapy. ${ }^{22}$ GNPs coated with Raman reporters can be used to detect target protein or tumors via surface-enhanced Raman detection. ${ }^{1,23}$ Finally, aptamer-conjugated GNP could prove to be drugs in their own right, since functionalized GNPs have previously been found to be useful for drug delivery. ${ }^{24}$ The binding and internalization assays that we have developed and applied in these studies should prove to be generally useful in moving GNP conjugates towards these applications.

\section{Supplementary Material}

Refer to Web version on PubMed Central for supplementary material.

\section{Acknowledgments}

This work was funded by the National Institutes of Health (R21 CA135315 and R01 EB003424) and the Welch Foundation (F-1654).

\section{Notes and references}

1. Qian X, Peng XH, Ansari DO, Yin-Goen Q, Chen GZ, Shin DM, Yang L, Young AN, Wang MD, Nie S. Nat Biotechnol. 2008; 26:83-90. [PubMed: 18157119]

2. Bhumkar D, Joshi H, Sastry M, Pokharkar V. Pharm Res. 2007; 24:1415-1426. [PubMed: 17380266]

3. Lee SE, Liu GL, Kim F, Lee LP. Nano Lett. 2009; 9:562-570. [PubMed: 19128006]

4. Rosi NL, Giljohann DA, Thaxton CS, Lytton-Jean AKR, Han MS, Mirkin CA. Science. 2006; 312:1027-1030. [PubMed: 16709779]

5. Gratton SE, Ropp PA, Pohlhaus PD, Luft JC, Madden VJ, Napier ME, DeSimone JM. Proc Natl Acad Sci USA. 2008; 105:11613-11618. [PubMed: 18697944]

6. Miller CR, Bondurant B, McLean SD, McGovern KA, O’Brien DF. Biochemistry. 1998; 37:1287512883. [PubMed: 9737866]

7. Singh AB, Harris RC. Cell Signal. 2005; 17:1183-1193. [PubMed: 15982853]

8. Carpenter G. Mol Cell Endocrinol. 1983; 31:1-19. [PubMed: 6309581]

9. Carpenter G. Cell. 1984; 37:357-358. [PubMed: 6327062]

10. Wen X, Wu QP, Ke S, Ellis L, Charnsangavej C, Delpassand AS, Wallace S, Li C. J Nucl Med. 2001; 42:1530-1537. [PubMed: 11585869]

11. Li N, Ebright JN, Stovall GM, Chen X, Nguyen HH, Singh A, Syrett A, Ellington AD. J Proteome Res. 2009; 8:2438-2448. [PubMed: 19271740]

12. Xiao Z, Shangguan D, Cao Z, Fang X, Tan W. Chemistry. 2008; 14:1769-1775. [PubMed: 18092308]

13. Giljohann DA, Seferos DS, Patel PC, Millstone JE, Rosi NL, Mirkin CA. Nano Lett. 2007; 7:3818-3821. [PubMed: 17997588]

14. Javier DJ, Nitin N, Levy M, Ellington A, Richards-Kortum R. Bioconjug Chem. 2008; 19:1309_ 1312. [PubMed: 18512972]

15. Seferos DS, Prigodich AE, Giljohann DA, Patel PC, Mirkin CA. Nano Lett. 2009; 9:308-311. [PubMed: 19099465]

16. Giljohann DA, Seferos DS, Prigodich AE, Patel PC, Mirkin CA. J Am Chem Soc. 2009; 131:2072-2073. [PubMed: 19170493]

17. Thiel KW, Giangrande PH. Oligonucleotides. 2009 
18. Medley CD, Smith JE, Tang Z, Wu Y, Bamrungsap S, Tan W. Anal Chem. 2008; 80:1067-1072. [PubMed: 18198894]

19. Xu H, Mao X, Zeng Q, Wang S, Kawde AN, Liu G. Anal Chem. 2009; 81:669-675. [PubMed: 19072289]

20. Sharma P, Brown S, Walter G, Santra S, Moudgil B. Adv Colloid Interface Sci. 2006; 123126:471-485.

21. Sokolov K, Follen M, Aaron J, Pavlova I, Malpica A, Lotan R, Richards-Kortum R. Cancer Res. 2003; 63:1999-2004. [PubMed: 12727808]

22. Hirsch LR, Stafford RJ, Bankson JA, Sershen SR, Rivera B, Price RE, Hazle JD, Halas NJ, West JL. Proc Natl Acad Sci USA. 2003; 100:13549-13554. [PubMed: 14597719]

23. Wang Y, Wei H, Li B, Ren W, Guo S, Dong S, Wang E. Chem Commun (Camb). 2007:52205222. [PubMed: 18060148]

24. Gibson JD, Khanal BP, Zubarev ER. J Am Chem Soc. 2007; 129:11653-11661. [PubMed: 17718495] 


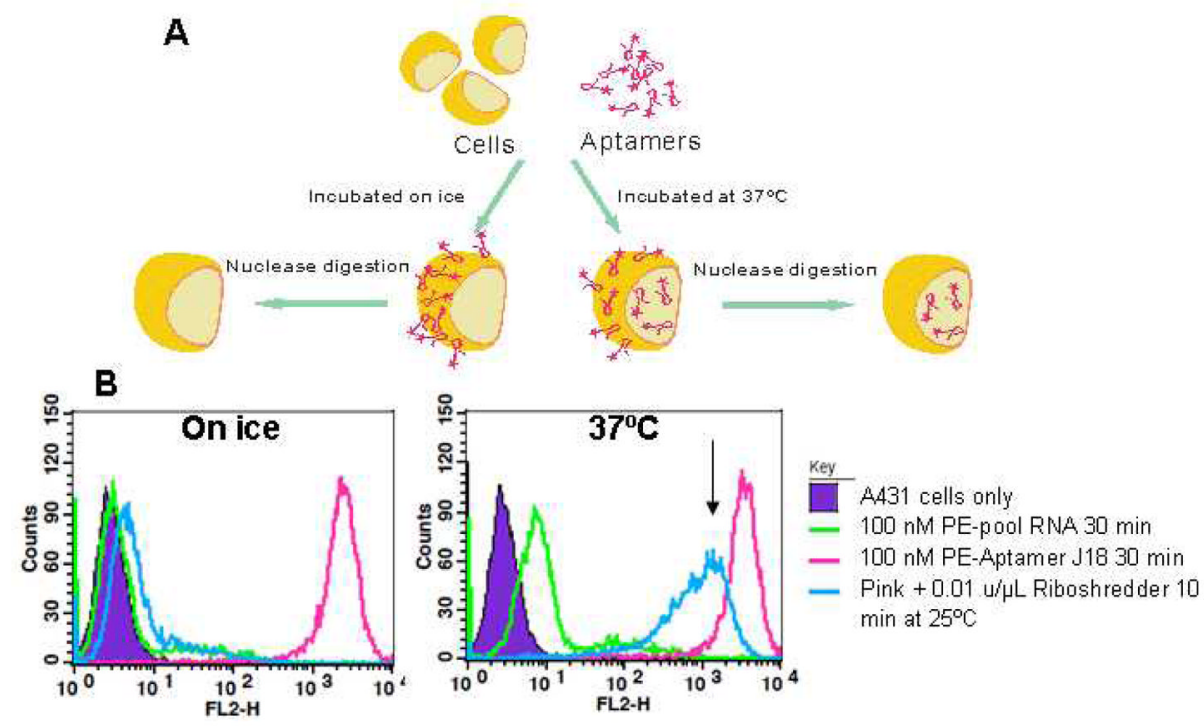

Fig. 1.

Internalization assay. (A) Schematic of internalization assay. (B) Internalization of antiEGFR aptamer. Phycoerythrin-labeled unselected N62 pool RNA (100 nM, green line) and PE-labeled Aptamer J18 (100 nM, pink line) were incubated with A431 cells either on ice (left) or at $37^{\circ} \mathrm{C}$ (right) for $30 \mathrm{~min}$. After the binding reaction, cells labeled with Aptamer $\mathrm{J} 18$ were further exposed to Riboshredder for $10 \mathrm{~min}$ at $25^{\circ} \mathrm{C}$ (blue line).. Internalized Aptamer J18 conjugates are indicated by arrows. 


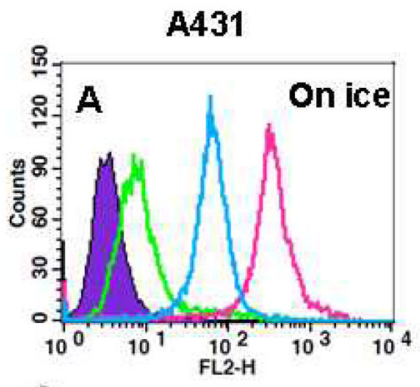

MDA-MB-435
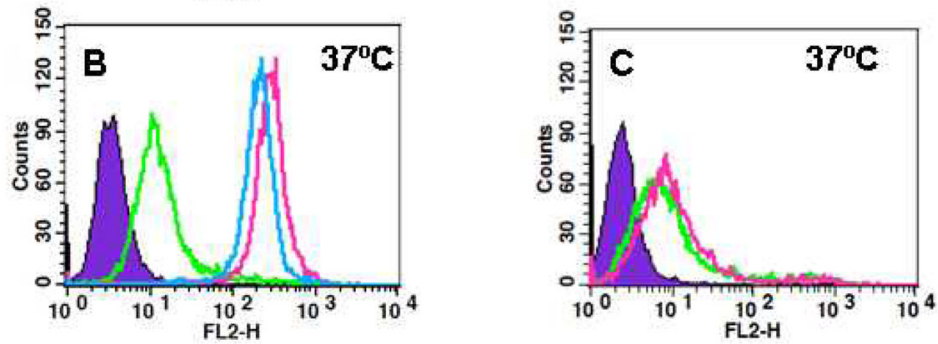

Fig. 2.

Aptamer-mediated internalization of GNP. A431 cells were incubated with PE-labeled Aptamer J18-GNP (pink line) and unselected N62 pool RNA-GNP (green line) either on ice (A) or at $37^{\circ} \mathrm{C}$ (B) for $30 \mathrm{~min}$. After the binding reaction, cells labeled with Aptamer J18GNP conjugates were further exposed to Riboshredder for $10 \mathrm{~min}$ at $25^{\circ} \mathrm{C}$ (blue line). As a negative control, MDA-MB-435 cells (C) were also incubated with PE-labeled Aptamer J18-GNP (pink line) and unselected N62 pool RNA-GNP (green line) at $37^{\circ} \mathrm{C}$ for $30 \mathrm{~min}$. 


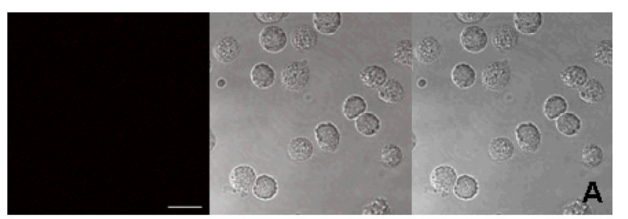

Scale bar $=20 \mu \mathrm{m}$
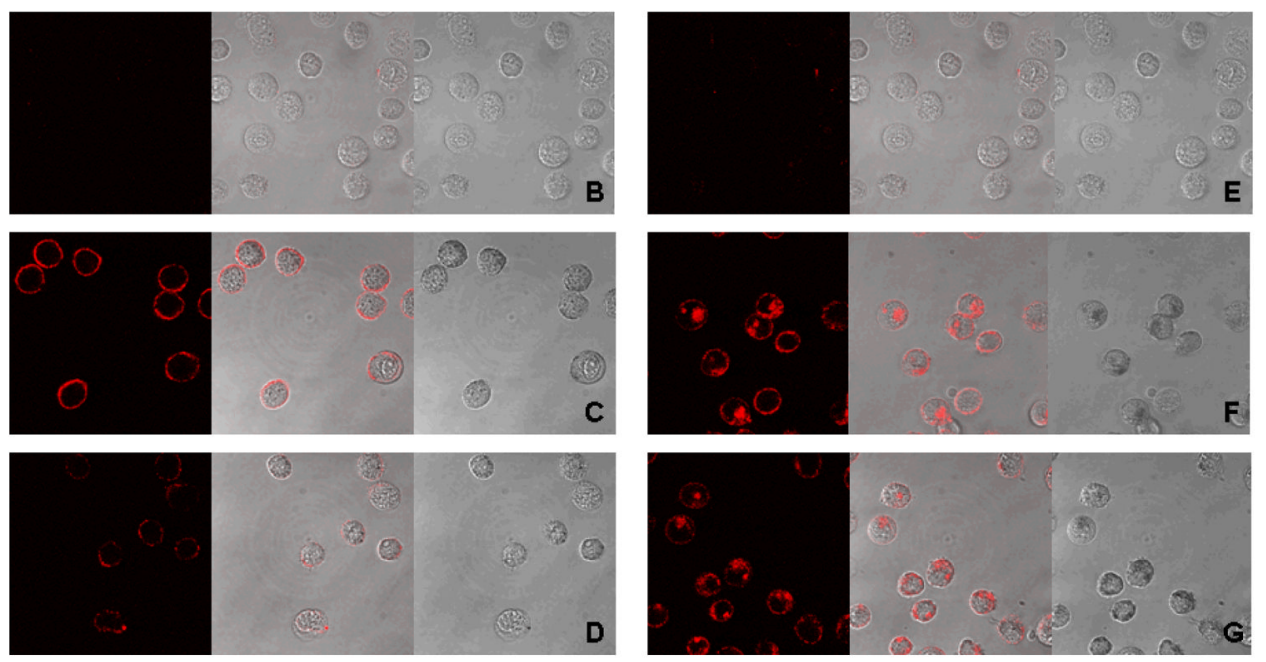

Fig. 3.

Microscopic detection of the internalization of Aptamer J18-GNP conjugates. A431 cells (A) were incubated with PE-labeled unselected N62 pool RNA-GNP on ice (B), PE-labeled Aptamer J18-GNP on ice (C), PE-labeled Aptamer J18-GNP on ice followed by Riboshredder treatment (D), PE-labeled unselected N62 pool RNA-GNP at $37^{\circ} \mathrm{C}$ (E), PElabeled Aptamer J18-GNP at $37^{\circ} \mathrm{C}(\mathrm{F})$, and PE-labeled Aptamer J18-GNP at $37^{\circ} \mathrm{C}$ followed by Riboshredder treatment $(\mathrm{G})$. Cell labeling was detected using a Leica confocal microscope with a $63 \times$ objective and $2 \times$ zoom, excitation at $543 \mathrm{~nm}$, and emission from $550-600 \mathrm{~nm}$. For all samples the confocal $z$-stack images were acquired at $1-\mu \mathrm{m}$ intervals for $20 \mu \mathrm{m}$ from the basal to the apical side of the cells. The images shown represent the maximum projections along the $x y$ axes of confocal stacks of 20 sections. Fluorescent images are on the left, bright field images are on the right and the overlays are in the middle. Scale bar, $20 \mu \mathrm{m}$. 